Wasiu Olalekan Olawole, 1,\# Kehinde Kazeem Kanmodi, 2-4,\#,* Abdulwarith Akinshipo ${ }^{5}$, Abdulrazzaq Olanrewaju Taiwo ${ }^{6}$

\title{
Anxiety In A Dental And Maxillofacial Surgery Consulting Room: Does Previous Experience Matter?
}

\author{
'Department of Dental and Maxillofacial Surgery, Federal Medical Centre, Birnin Kebbi, Nigeria \\ 'World Health Organization, Kebbi State Field Office, Birnin Kebbi, Nigeria \\ ${ }^{3}$ Cephas Health Research Initiative Inc, Ibadan, Nigeria \\ ${ }^{4}$ Healthy Mind Program, Mental and Oral Health Development Organization, Kalgo, Nigeria \\ ${ }^{5}$ Department of Oral Biology and Oral Pathology, Faculty of Dental Science, University of Lagos, Lagos, Nigeria \\ ${ }^{6}$ Department of Dental and Maxillofacial Surgery, Usmanu Danfodiyo University Teaching Hospital, Sokoto, Nigeria \\ *email: kanmodikehindelayahoo.com \\ "Equal contributions
}

DOI: 10.2478/gp-2019-0014

Received: 9 February 2019; Accepted: 16 July 2019

\begin{abstract}
Objectives: To explore the associations between previous dental visits and dental anxiety among patients presenting at the dental and maxillofacial surgery clinic of Department of Dental and Maxillofacial Surgery, Federal Medical Centre, Birnin Kebbi, Nigeria. Materials and methods: This study was a cross-sectional study conducted among 172 patients. Study instrument was a 9-item structured questionnaire, which obtained information about the participants regarding their: demographic profile; previous dental experience; and dental anxiety status in a dental and maxillofacial surgery consulting room. Data collected were analyzed using the SPSS Version 20 Software. Associations between variables were evaluated using Chi-square statistics using a $p<0.05$ to determine the level of statistical significance.

Results: Roughly, six-tenth (57.6\%) of the participants were males. The observed prevalence of dental anxiety among the participants was 47.7\%. A history of pain experience during past dental treatment as well as a history of past dental visit were found to have statistically significant relationships with participants' dental anxiety status (p-values $<0.05)$. However, the frequency of previous dental visits, a history of past dental treatment, and a history of use of intraoral injections in the course of past dental treatment were found to have no statistically significant relationship with participants' status of dental anxiety ( $p$-values $>0.05)$. Finally, the prevalence of dental anxiety among the groups of female folks with "a history of previous visit to a dentist" and " $\mathrm{a}$ history of pain experience in the past dental treatment" were found to be significantly higher than that observed among similar groups among the male folks ( $p$-values < 0.05).

Conclusion: Previous experience of pain plays a major role of influence over dental anxiety experience among patients. Hence, dental practitioners need to pay more attention towards dental anxiety management among patients, especially women.
\end{abstract}

\section{Keywords}

Dental anxiety, dentist, dental, maxillofacial, surgery, experience, patient, pain management, treatment, Nigeria

\section{INTRODUCTION}

Dental anxiety can be defined as abnormal fear or dread of visiting the dentist for preventive care or therapy and unwarranted anxiety over dental procedures (Reference.MD, 2018). This clinical condition is a major factor contributing to patients' refusal for treatment at a dental surgery (Skaret et al., 1999, Scheutz \& Heidmann, 2001, Hittner \& Hemmo, 2009). Dental anxiety is a serious public health problem affecting a very significant proportion of the population (Smith \& Heaton,
2003, Klinberg \& Broberg, 2007, Astrom et al., 2011) and its prevalence varies across populations, ranging between 4 and 20\% (Horst \& De Wit, 1993, Moore et al., 1993, Locker et al., 1996, Udoye et al., 2005, Nicolas et al., 2007, Arigbede et al., 2011).

Pertinently, people with dental anxiety do bypass the use of proper oral healthcare services and resort to self-care and use of alternative care (such as use of herbal medicines); making many of them suffer from poor oral health conditions 
(Berggren \& Meynert, 1984, Locker, 1995, Doebling \& Rowe, 2000, Armfield et al., 2007). Previous studies had shown that people with prior clinical contact with dentists are more likely to have dental anxiety when compared with those with no such contact (Akhigbe \& Koleoso, 2014, Eroglu et al., 2017).

Previous pain experience in a dental procedure is a major predictor of anxiety among dental patients (Fiset et al., 1989, Vassend, 1996). Interestingly, in the field of dentistry, there are various methods that can be used in the management of pain and dental anxiety; some of these methods include psychological management, use of sedatives, anxiolytics, and general anesthesia (Maggiras \& Locker, 2002, Patricia et al., 2014). These aforementioned methods are used in patients' management with the sole aim of bringing dental anxiety and pain to the barest minimum among dental patients.

In Nigeria, different studies had been conducted in exploring issues of dental anxiety among patients and dentists (Udoye et al., 2005, Arigbede et al., 2011, Patricia et al., 2014). However, only few of these studies explored the association between history of previous dental visit and anxiety among dental patients. Also, to the best of our knowledge, no published study on dental anxiety had been conducted at any dental center in Kebbi State, Nigeria. Hence, this study aims to explore the associations between previous dental visit and dental anxiety among a sample of non-pediatric patients, who are presenting at the Department of Dental and Maxillofacial Surgery, Federal Medical Centre, Birnin Kebbi, Kebbi State, Nigeria. Conducting this kind of study in this health facility is of high benefit, as the findings from this study will add to the body of knowledge on dental anxiety among the Nigerian patients. Also, this health facility is a referral center to all dental clinics in the entire Kebbi State; hence, the research data provided from this study will give an overview on these parameters of interest among dental patients in Kebbi.

\section{MATERIALS AND METHODS}

This was a cross-sectional study conducted among the patients attending the Department of Dental and Maxillofacial Surgery, Federal Medical Centre, Birnin-Kebbi, Nigeria, from July to October, 2016. This study forms part of the "Dental Health Services Project" conducted in the aforementioned department (Olawole \& Kanmodi, 2019).

The instrument used for this study was a 9-item structured questionnaire, which obtained information about the participants regarding their: demographic profile, previous dental experience, and dental anxiety status in the dental and maxillofacial surgery consulting room. The questionnaire was developed from related published studies on dental anxiety (Hmud \& Walsh, 2007, Arigbede et al., 2011).Thereafter, the questionnaire was reviewed, revised and approved by a senior dentist/researcher and health educator prior to its use in the study. The final version of the questionnaire was used to collect data for the study.

The minimum sample size for this study $(\mathrm{n}=166)$ was calculated using the Leslie formula for study population < 10,000 at a prevalence rate of dental anxiety of $12.3 \%$ derived from a previous study among dental patients (Leslie, 1965; Kusekwa \& Kikwilu, 2011).

The criteria used for the selection of participants are as follows:

- Being a non-pediatric dental patient (aged 16 years and above)

- Patients who had concluded a clerking session with a dentist but are yet to receive treatment for the conditions they were being diagnosed of

Only those patients that met the above selection criteria were recruited for the study. Prior to participation, the participants were informed about the purpose of the study; they were also informed that their participation is anonymous and completely voluntary. Only those $(n=172)$ that gave verbal informed consent were recruited for the study. All the questionnaires were administered by the primary investigator. Data collected was cleaned, coded, and analyzed using the SPSS Version 20 Software. Frequency distribution of all variables were determined and test of associations between variables were done using the Chi square $\left(X^{2}\right)$ test, with a p-value $<0.05$ used to determine the level of statistical significance. Results were presented using a table and a chart.

\section{RESULTS}

A total of 172 participants were used for the study. The majority of them were males (57.6\%), Muslims (73.8\%) and within the age range of 16 to 35 years (65.1\%). Also, $33.7 \%$ were single, while only $40.1 \%$ had polytechnic/university education.

Less than half $(82 / 172$ [47.7\%]) of the participants experienced anxiety in the dental and maxillofacial surgery consulting room. Table 1 shows the comparison between the participants' history of ever visiting a dentist and their dental anxiety status. The frequency of past dental visits, a history of past dental treatment, and a history of use of intraoral injections in the course of past dental treatment were found to have no statistically significant relationship with participants' dental 
Table 1. Effects of previous dental experience on current anxiety status

\begin{tabular}{|c|c|c|c|c|c|c|c|c|c|c|}
\hline \multirow[t]{3}{*}{ Variables } & \multirow[b]{3}{*}{ Response } & \multicolumn{9}{|c|}{ Are you afraid now?* } \\
\hline & & \multicolumn{3}{|c|}{ Male ( $N=99)$} & \multicolumn{3}{|c|}{ Female ( $N=72)$} & \multicolumn{3}{|c|}{ Uncategorized ( $N=172)$} \\
\hline & & Yes & No & $p(d f)$ & Yes & No & $p(d f)$ & Yes & No & $p(d f)$ \\
\hline \multirow{2}{*}{$\begin{array}{c}\text { Have you } \\
\text { ever visited a } \\
\text { dentist?a }\end{array}$} & Yes & 37 & 46 & \multirow{2}{*}{0.230 (1) } & 40 & 24 & \multirow{2}{*}{$0.113(1)$} & 77 & 70 & \multirow{2}{*}{$0.049(1)$} \\
\hline & No & 3 & 9 & & 2 & 5 & & 5 & 14 & \\
\hline \multirow{9}{*}{$\begin{array}{c}\text { If yes (to } \\
\text { above }{ }^{\mathrm{a}} \text {, } \\
\text { number of visits }\end{array}$} & 1 & 10 & 11 & \multirow{9}{*}{$0.229(8)$} & 5 & 6 & \multirow{9}{*}{$0.118(5)$} & 15 & 17 & \multirow{9}{*}{$0.151(8)$} \\
\hline & 2 & 7 & 19 & & 17 & 13 & & 24 & 32 & \\
\hline & 3 & 9 & 8 & & 13 & 2 & & 22 & 10 & \\
\hline & 4 & 4 & 3 & & 6 & 3 & & 10 & 6 & \\
\hline & 5 & 2 & 4 & & $* * *$ & $* * *$ & & 2 & 4 & \\
\hline & 6 & 2 & 1 & & $* * *$ & $* * *$ & & 2 & 1 & \\
\hline & 7 & 1 & 0 & & 0 & 1 & & 2 & 1 & \\
\hline & 9 & 1 & 0 & & $* * *$ & $* * *$ & & 1 & 0 & \\
\hline & 10 & 0 & 2 & & 0 & 1 & & 0 & 3 & \\
\hline \multirow{2}{*}{$\begin{array}{c}\text { Have you } \\
\text { had dental } \\
\text { treatment done } \\
\text { before? }^{\mathrm{b}} \\
\end{array}$} & Yes & 35 & 46 & \multirow[b]{2}{*}{$0.920(1)$} & 39 & 23 & \multirow[b]{2}{*}{0.606 (1) } & 74 & 69 & \multirow[b]{2}{*}{0.544 (1) } \\
\hline & No & 5 & 7 & & 2 & 2 & & 7 & 9 & \\
\hline \multirow{2}{*}{$\begin{array}{l}\text { If yes (to } \\
\text { above }^{\text {b), was }} \\
\text { it a painful } \\
\text { treatment? }\end{array}$} & Yes & 25 & 22 & \multirow[b]{2}{*}{0.033 (1) } & 34 & 6 & \multirow[b]{2}{*}{$<0.0001(1)$} & 59 & 28 & \multirow[b]{2}{*}{$<0.0001$ (1) } \\
\hline & No & 10 & 24 & & 5 & 16 & & 15 & 40 & \\
\hline \multirow{2}{*}{$\begin{array}{c}\text { If yes (to } \\
\text { above }^{\text {b), was an }} \\
\text { injection given } \\
\text { to you in your } \\
\text { mouth? }\end{array}$} & Yes & 25 & 31 & \multirow[b]{2}{*}{0.925 (1) } & 35 & 15 & \multirow[b]{2}{*}{$0.035(1)$} & 60 & 46 & \multirow[b]{2}{*}{0.117 (1) } \\
\hline & No & 10 & 13 & & 4 & 7 & & 15 & 22 & \\
\hline
\end{tabular}

${ }^{*}$ Only the data of those participants that responded to the cross-tabulated variables were computed in this statistics; ${ }^{* * *}$ No data; $\mathrm{N}-$ Total number of participants in each category

anxiety status (p-values < 0.05). However, a history of pain experience during past dental treatment had a statistically significant relationship with participants' status of dental anxiety ( $p$-value $<0.0001$ ): a higher proportion $(59 / 87)$ of those participants with painful experience during their past dental treatment had dental anxiety when compared to their counterparts (19/55) with no pain experience during their past dental treatment. Also, a history of previous dental visit had a statistically significant relationship with participants' status of dental anxiety ( $\mathrm{p}$-value $=0.049)$.

Finally, the prevalence of dental anxiety among the groups of female folks with "a history of previous visit to a dentist" and "a history of pain experience in the past dental treatment" were found to be significantly higher than that observed among similar groups among the male folks ( $p$-values $<0.05$ ) (Table 1).

\section{DISCUSSION}

Dental anxiety is a problem of global health importance (Facco \& Zanette, 2017). Dental anxiety is also a major cause of refusal for dental treatments among people with oral health-related problems (Skaret et al., 1999, Scheutz \& Heidmann, 2001, Hittner \& Hemmo, 2009). However, it is alarming that many patients with dental anxiety do suffer from deteriorating oral health conditions, which do eventually cause negative effects on their quality of life (Berggren \& Meynert, 1984, Locker, 1995, Doebling \& Rowe, 2000, Armfield et al., 2007).

In this study, as high as $47.7 \%$ of the participants reported that they were having dental anxiety at the dental and maxillofacial consulting room. This statistics is higher than that reported among the general populations (Horst \& De Wit, 1993, Moore et al., 1993, Locker et al., 1996, Udoye et al., 2005, Nicolas et al., 
2007, Arigbede et al., 2011). The reason for this high prevalence rate of dental anxiety among the participants in this study may probably be due to the issue that they were already having oral health problems, which they might have felt that it could only be treated or resolved through a painful dental procedure.

Furthermore, this study also observed that those participants with a positive history of past dental visit, especially those who experienced pain during the course of the treatment done for them in their past visit(s), formed the significant majority of those respondents who reported to have anxiety. The findings recorded in this study were found to be similar to the reports in the literatures (Akhigbe \& Koleoso, 2014; Eroglu et al., 2017).

It is also noteworthy that not so many of those participants who received intraoral injection from a dentist, in their past dental visit, experienced dental anxiety. A justifiable reason for this situation may be due to the analgesic effect they experienced after receiving the injection; such analgesic experience probably goes a long way in making a patient calm in subsequent visits.

This current work also demonstrated that a higher proportion of the female participants had dental anxiety as when compared with the male participants. This observation is similar with that reported in other studies (Doerr et al., 1998, Bergadhl \& Bergadhl, 2003, Sghaireen et al., 2013, Saatchi et al., 2015). In fact, research had clearly shown that females have higher pain sensitivity than males (Bartley \& Fillingim, 2013); this implies that females are supposed to be more dentally anxious than males.

\section{Limitations}

However, this study has some limitations. This study was a single-center study; this study did not survey other dental clinics situated within Birnin Kebbi as well as in other towns in Kebbi State. Therefore, it is difficult to use the findings made in this study to make generalizations on the prevalence of dental anxiety in Kebbi State. Moreover, the present work only utilized a population of non-pediatric patients; hence, patients that fell within the age range of 0 to 16 years were not captured in this study. This shows the need for a similar study on pediatric population in Kebbi State.

\section{Recommendations}

Based on the above, the authors of this study make the following recommendations: [1] dental care providers should always endeavor to ensure that all dental procedures are as painless as possible in order to allay anxiety among dental patients; [2] dental care providers should always endeavor to educate their patients on a treatment procedure prior to the start of such procedures; [3] dental care providers should always pay extra attention to the psychological management of dental anxiety among male patients, as well as those patients with positive history of painful treatment, at each of their visits to the dental office; [4] researchers should also endeavor to explore the dental anxiety experience among pediatric patient population in Kebbi State, Nigeria.

\section{CONCLUSIONS}

The findings from this present study reveals that previous dental treatment experience has significant influence over dental anxiety among patients during their subsequent visits to a dental and maxillofacial surgery clinic. Also, females are often more dentally anxious than males.

\section{FUNDING}

This study was self-funded.

\section{CONFLICT OF INTEREST}

Authors have no issue of conflict of interest to declare.

\section{DECLARATION OF ETHICS}

This study was conducted under strict compliance with the Helsinki Declaration of 1964. The study protocol was approved by the Research Ethics Committee of the Federal Medical Centre, Birnin Kebbi, Nigeria.

\section{DECLARATION OF INFORMED CONSENT}

Verbal informed consent was obtained from all participants. Data obtained from participants were kept confidential and all participation was voluntary. 


\section{REFERENCES}

Akhigbe KO, Koleoso ON. Trait anxiety, sex, age and dental treatment experience as determinants of dental anxiety among chronic dental patients in Nigeria. Eur Sci J 2014;10(12):316-28.

Arigbede AO, Ajayi DM, Adeyemi BF, Kolude B. Dental anxiety among patients visiting a university dental centre. Nig Dent J 2011;19(1):20-4.

Armfield JM, Stewart JF, Spencer AJ. The vicious cycle of dental fear: exploring the interplay between oral health, service utilization and dental fear. BMC Oral Health 2007;14(7):1.

Astrom AN, Skaret E, Haugejorden O. Dental anxiety and dental attendance among 25-year-olds in Norway: time trends from 1997 to 2007. BMC Oral Health 2011;11:10.

Bartley EJ, Fillingim RB. Sex differences in pain: a brief review of clinical and experimental findings. Br J Anaesth 2013;111(1):52-8.

Bergdahl M, J Bergdahl. Temperament and character personality dimensions in patients with dental anxiety. Eur J Oral Sci 2003;111(2):93-98.

Berggren U, Meynert G. Dental fear and avoidance - causes, symptoms and consequences. J Am Dent Assoc 1984;109:247-51.

Doebling S, Rowe MM. Negative perceptions of dental stimuli and their effects on dental fear. J Dent Hyg 2000;74:110-6.

Doerr PA, Lang WP, Nyquist LV, Ronis DL. Factors associated with dental anxiety. J Am Dent Assoc 1998;129(8):1111-19.

Eroglu CN, Ataoglu H, Kucuk K. Factors affecting anxiety-fear of surgical procedures in dentistry. Niger J Clin Pract 2017;20:409-14.

Facco E, Zanette G. The odyssey of dental anxiety: From prehistory to the present. A narrative review. Front Psychol 2017;8:1155.

Fiset L, Milgrom P, Weinstein P, Melnick S. Common fears and their relationship to dental fear and utilization of the dentist. Anesth Prog 1989;36:258-64.

Hittner JB, Hemmo R. Psychosocial predictors of dental anxiety. J Health Psychol 2009;14:53-9.

Horst G, De Wit CA. Review of behavioural research in dentistry 1987-1992: Dental anxiety, dentist-patient relationship, compliance and dental attendance. Int Dent J 1993;43:265-73.
Hmud R, Walsh LJ. Dental anxiety: Causes, complications and management approaches. Int Dent SA 2007;9(5):6-14.

Klinberg G, Broberg AG. Dental fear/anxiety and dental behavior management problems in children and adolescents: a review of prevalence and concomitant psychological factors. Int J Paediatr Dent 2007;17:391-406.

Kusekwa M, Kikwilu EN. Reasons for late seeking of dental care among dental patients attending dental clinics at School of Dentistry MUHAS, Tanzania. Tanzania Dent J 2011; 17(1):7-14.

Leslie K. Survey sampling. New York: John Wiley and Sons, Inc. 1965.

Locker D. Psychological consequences of dental fear and anxiety. Community Dent Oral Epidemiol 1995;23:259-61.

Locker D, Shapiro D, Liddell A. Who is dentally anxious? Community Dent Oral Epidemiol 1996;24:346-50.

Nicolas E, Collado V, Faulks D, Bullier B, Hennequin M. A national cross-sectional survey of dental anxiety in the French adult population. BMC Oral Health 2007;7:12.

Moore R, Birn H, Kirkegaard E, Brodsgaard I, Scheutz F. Prevalence and characteristics of dental anxiety in Danish adults. Community Dent Oral Epidemiol 1993;21:292-6.

Maggiras J, Locker D. Psychological factors and perceptions of pain associated with dental treatment. Community Dent Oral Epidemiol 2002;30:151-9.

Olawole WO, Kanmodi KK. Factors responsible for delayed presentation at the dental clinic of the Federal Medical Centre, Birnin Kebbi, Nigeria. Med Univ 2019;2(1):12-20.

Patricia A, Opeyemi AB, Micah GO, Emeka Cl, Adesida AA. Management of dental anxiety: A survey of Nigerian dentists. Sahel Med J 2014;17:159-63.

Reference.MD. Dental anxiety. [Internet]. Available from: http:// www.reference.md/files/D016/mD016854.html

Udoye $\mathrm{Cl}$, Oginni AO, Oginni FO. Dental anxiety among patients undergoing various dental treatments in a Nigerian teaching hospital. J Contemp Dent Pract 2005;6(2):91-8. 
Saatchi M, Abtahi M, Mohammadi G, Mirdamadi M, Binandeh ES. The prevalence of dental anxiety and fear in patients referred to Isfahan Dental School, Iran. Dent Res J 2015;12:248-53.

Scheutz F, Heidmann J. Determinants of utilization of dental services among 20- to 34-year-old Danes. Acta Odontol Scand 2001;59:201-11.

Sghaireen MG, Zwiri AMA, Alzoubi IA, Qodcieh SM, Al-Omiri MK. Anxiety due to dental treatment and procedures among university students and its correlation with their gender and field of study. Int J Dent 2013;2013:647436.

Skaret E, Raadal M, Berg E, Kvale G. Dental anxiety and dental avoidance among 12-18-year olds in Norway. Eur J Oral Sci 1999;107:422-8.

Smith TA, Heaton LJ. Fear of dental care: are we making any progress? J Am Dent Assoc 2003;134:1101-8.

Vassend 0. Anxiety, pain and discomfort associated with dental treatment. Behav Res Ther 1993;31:659-66. 